\title{
Analysis of the Relationship Between Modern Sculpture and Ecological Harmony
}

\author{
Hong Su \\ Weifang University of Science and Technology, ShanDong ShouGuang, 262700,China.
}

Keywords:Ecological view; Sculpture market; Sculpture and ecology; Harmonious relationship

\begin{abstract}
This paper from the aspect of the environment and the spiritual ecology of sculpture works to explore the significance of sculpture to create ecological space. This paper summarizes the ecological concept and the ecological status of Chinese sculpture, analyzes the present situation of China modern sculpture market. Put forward the important significance of developing ecological sculpture market and studied the ecological development of sculpture industry measures. This paper points out that we should make a perfect combination of sculpture and ecology.
\end{abstract}

\section{Introduction}

Now, with the advent of the sculpture market, unreasonable material using and market system is not perfect and many problem is becoming more and more serious, the harmony of ecology and sculpture has become the focus of attention of artists and many entrepreneurs, China's modern sculpture market facing serious ecological imbalance, these undesirable phenomena forcing people to establish a new attitude to the sculpture, sculpture development of ecology. Ecology and ecological thinking society is gradually becoming the primary concern and thinking. It will be for modern sculpture art brought important influence, and become the highest pursuit of modern sculpture market and will eventually become the development direction of modern sculpture art.

\section{Ecological view and sculpture ecological status qua}

Overview of ecological view. The ecological view points out the whole earth, and even the universe, is an ecosystem, and the ecological view can be summarized as three species: the broad ecosystem view, the basic view and the view of the intersection. The broad ecosystem thinks that people can interfere with the system according to their intention to achieve their goals.. The economic development of human society must comply with the law of ecological development, and can't exchange the ecological environment for economic development.. In view of the intersection of ecological view, man has the ability to disturb the ecosystem and can realize his goal according to his own intention and the law of nature.

The ecological status of Chinese sculpture. Since the founding of new China, especially since the reform and opening up, China has gradually established the environmental protection basic national policy, promote the harmonious development of man and nature, put forward to build a resource-saving and environment-friendly society, the construction of ecological civilization. Ecological sculpture is gradually developed in this social environment.Ecological sculpture from philosophy, is the ecological thinking, ecological world view and ecological ethics of all kinds of cultural ideas of the reminder; from the perspective of aesthetics, ecological sculpture is the product of ecological aesthetics. Establish the ecological idea of sculpture can we call for ecological sculpture, but the starting point end point is oriented to promote people's all-round development, and continuously meet the needs of urban people's physiological and psychological and emotional and cultural. So sculpture is good or bad, not only simple and mechanical evaluation of works of artistic value, to the neglect of generated in the process and the process of its and ultimately to express meaning. That is to 
say, a sculpture project, at the beginning of the design to the final completion of the entire process, the needs of artists and the public forms its intrinsic value, and a direct impact on the societal value of the sculpture. I think here of a sense, the significance of this process is far greater than the artistic value of sculpture itself, and fundamentally determines the success or failure of sculpture works.

\section{The development of modern sculpture in China}

The formation of modern sculpture market. The formation of a new market is based on the economic development of the society as the basis and the people's needs.. And now China has basically had. With the rapid development of China's economy, world cultural exchanges so as to promote the improvement of a new generation of visual art pursuit and aesthetic ability; coupled with China's huge population, formed the new market provides an invaluable source of development.

Problems and future trend of Chinese Sculpture Market. There are many factors that affect the development of modern sculpture market in China. Such as the level of government leadership management, planning department of the sculpture market planning, the ultimate pursuit of the artist in the creation, the comprehensive quality of the public, etc.. Secondly, from the perspective of environmental art, sculpture cannot be integrated with the space environment, scale, shape, background and other factors. Here are some of the questions that I have frequently occurred and I have analysed it.

Material misuse, resource consumption

In recent years, China has established a number of considerable sculpture works. The number of sculptures in cities across the country rose. Most of the city sculpture played a decisive role in the city, beautify the environment. But there is a large number of sculptures and not because the material system and rough on the environment caused some negative effects. The city sculpture, it not only can improve the city environment and harmony environment culture atmosphere. City sculpture according to its material can be subdivided into metal and nonmetal materials, metal materials including copper, iron, titanium, stainless steel, non-metallic contains marble, glass, etc.. Glass and steel has its obvious defects, in under the action of wind, sand, rain and snow, chemical medium, temperature high fever easily leads to aging phenomena. And the place where the wind blew sand is not high in the marble. Unreasonable use of sculpture materials is not only the waste of time resources also can cause negative effect on the environment, which is enough for the sculpture artists and we reflect deeply.

Creative, inferior imitation copy

The pace of the sculpture works is accelerating. But in the pursuit of efficiency, there are some creative sculptures. Sculpture should express a unique artistic form, emphasize and pursue its cultural connotation, the lack of ideological depth of the sculpture creation, can only be inferior works. The 21st century is the era of information network, people just seat in front of the computer can understand abroad many, many outstanding sculpture. At the same time, it is convenient to steal ideas, so market continue to emerge a copy from the move, I had in Lotte Tao agency creative city set to see the many humble plagiarism, they only get the money for the purpose, a rough idea shallow or directly copy others creative sculpture.

Sculptures in the future not only appear in the garden hall, and will be people into the tens of thousands of households and the market development is immeasurable. A group of vibrant sculpture creators, sculptor, the era of the demand for Dongfeng, will let the sculpture market, like mushrooms, diffuse rotten throughout the country.

\section{The significance of ecological popularization of sculpture market}

The importance of ecology to sculpture design. Sculpture art is the space art and visual art. It is closely linked to the ecological environment. Ecological and sculpture art in terms of form, space and 
culture, mutual penetration, influence each other, sculpture and ecology should be harmonious and unified. In a word, is sculpture, environment, culture there should be harmonized (Fig. 1). Anyone piece of sculpture in the environment, must be the environment in the form of the overall contact and echo. Otherwise, it will lead to the formation of conflicts in the form of sculptures and environmental space.

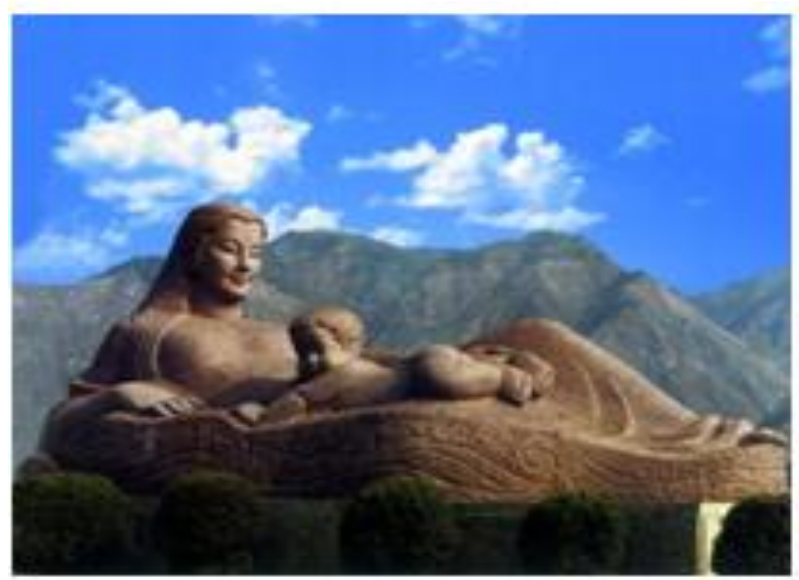

Fig. 1 The Yellow River mother

The sculpture design should merge nature. Any form with art and nature, and achieve the highest realm of heaven and earth joins. A successful artist has always been about the "nature" and "nature". The creation of sculpture works, we must first integrate the external form and the beauty of nature in the specific environment, and achieve the effect of the natural ecological harmony and symbiosis.. The sculptor has various means to achieve the effect of harmony with nature. For example, by borrowing, forming an atmosphere of psychological induction and other means to achieve mutual promotion come true artistic atmosphere and scene. Such as Japanese sculptor Sekine Nakao works "empty like" (such as in Fig. 2). With the help of stainless steel mirror mapping, to around the sky, trees, mapping the characters into the works, make simple shape becomes rich in content, let environment and work associated with each other, mutual benefit. The entrance to the underground engineering of famous architect I. M. Pei designed Louvre reconstruction, modeling source in ancient Egypt tapered square pyramid (Fig. 3), combined with a very modern glass and interpretation of both ancient and traditional civilization, and endows the work with the new trend of the atmosphere and the industrial era sense of rhythm, is worthy of a sculpture and modern urban environment perfect symbiosis model.

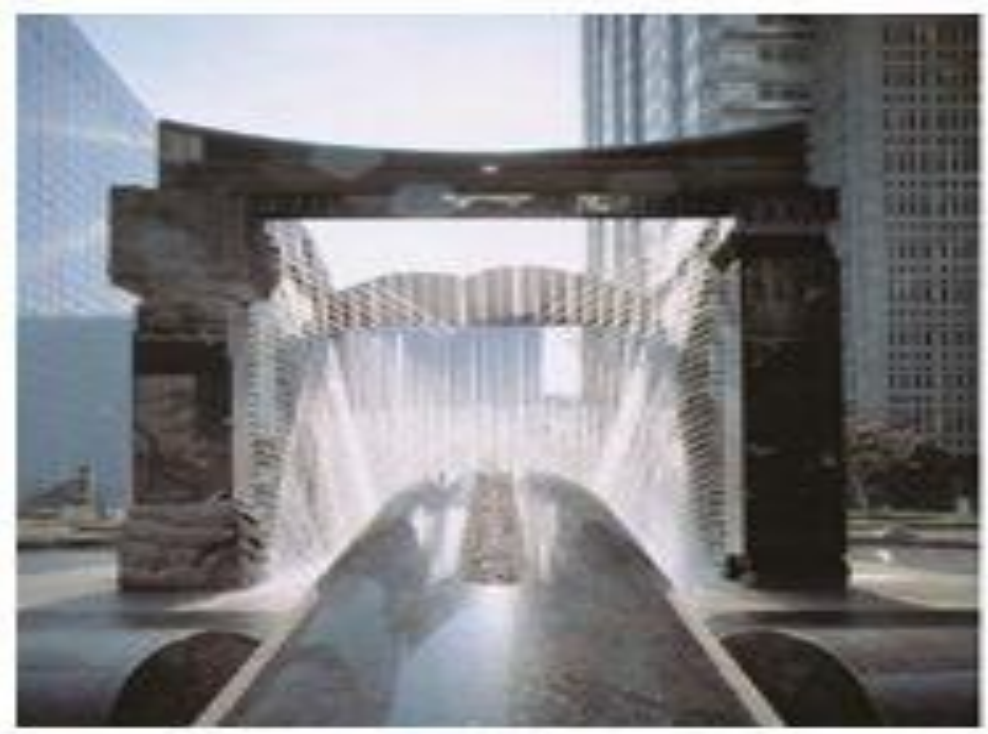

Fig. 2 Like empty 


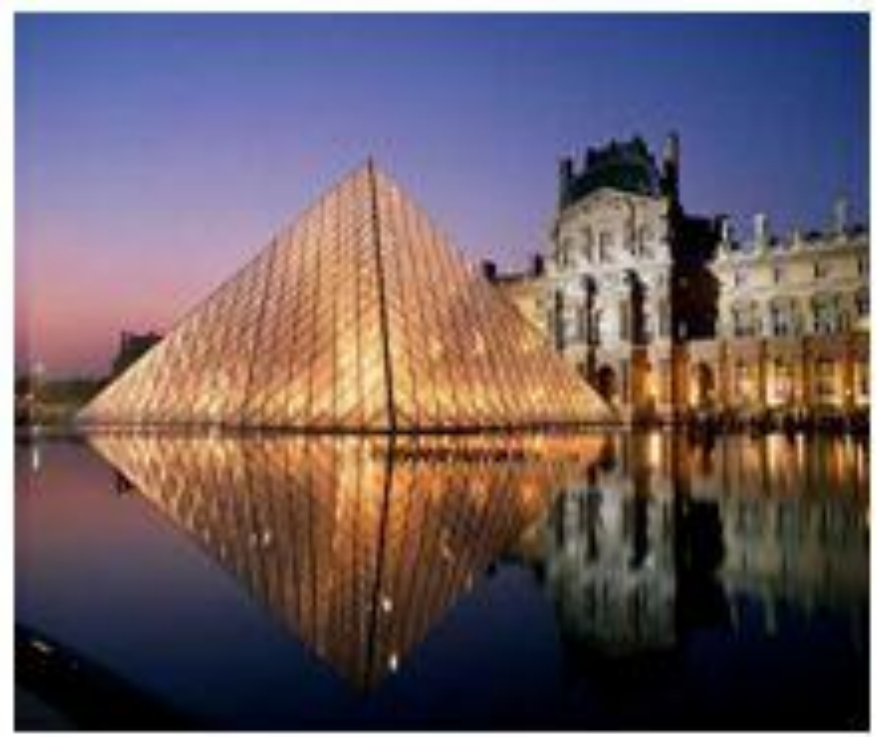

Fig. 3 Glass Pyramid

The harmonious function of sculpture and ecology. Modern social cultural environment performance for man and nature of the confrontation, with rational apathy and fanatical occupy the human crowding into a corner, the intense social reality, reducing the people's spiritual life and material serious infiltration people's physical and mental, lost the spiritual home, is a kind of spiritual ecological imbalance, people in apathy and numbness at the same time, began to miss "mining Ju tori, carefree and leisurely see Nanshan" unsophisticated and nature. Sculpture seeks to cure the continual widening interval between human and nature, according to the characteristics of different times, adjust the spiritual ecological needs. In the growing process of the adult industry and the increasingly indifferent interpersonal relationship, the work of art can make people return to nature and simplicity, and make the life of the person more tender and tender. The sculpture can through the shape, texture, form and environment forming aesthetic form, meets the demand of human vision, is beneficial to appease the modern people's psychological, the heart can draw a peaceful, lasting natural beauty, beautiful feeling of life, give the fatigue of the urban people's soul comfort.

\section{Measures for developing eco sculpture industry}

Organizational ecology Sculpture Committee and advocate the ecological problems of concern to the masses; sculpture and ecological harmony should be unified planning; resist the low quality of the sculpture, the establishment of ecological, scientific, conservation, human sculpture market

\section{Conclusions}

For ecological thinking of sculpture culture, we need to know more of the social or human nature of our life.. We have only just begun to discuss the humanistic concern of the sculpture market and the cultural ecology, and it is still superficial and superficial to the contemporary art sculpture.. For ecological culture and art on a human thinking and measure criterion of art connotation, sculpture can be regarded as an appropriate combination of import point, a hidden possibility of tremendous power, it is to face the future and, guide Chinese culture and art to higher level, the development of the road.

\section{References}

[1] Linmao Guang. Ecological sculpture. Shandong Art Press. 
[2] Third session of the city sculpture construction achievements collection. National urban sculpture construction Steering Committee compiled.2005.8.

[3] Jian Yang. Analysis of abstract sculpture and environment application. Journal of Liangshan University, 200304.

[4] Ainian Li. The eco civilization construction calls for the eco of environmental law, the ecological civilization and the environmental resources law, the National Environmental Resources Law Seminar (annual meeting), [C], 2009:98-110.

[5] Changan Lu. The problems and Countermeasures of ecological civilization construction in China [D]. the CPC Hubei provincial Party school, 2010. 